INDIAN JOURNAL OF POWER \& RIVER VALLEY DEVELOPMENT www.ijprvd.info

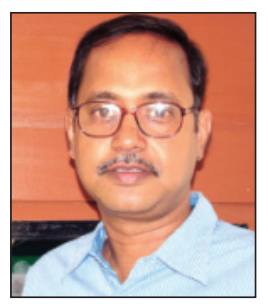

\title{
The survival codes of power industry in slowing economy
}

Studies in the USA and the Europe find that in the last decade industry players with (1) a greener energymix, (2) smaller scale and, quite naturally, (3) better financial performance fared better than the others. New business models and the most adaptive business models succeeding are those that circle around the customer interface with fast digital solutions. The flexible interplay between consumption and production of energy, and/or between several service alternatives to fulfill basic needs for customer comfort proved important.

In spite of the moves towards a greener energy mix, the US and the European companies remained solidly anchored in conventional generation. From 2000-2007 and then 2008 till date, the carbon share of power generation has only decreased by about one to two per cent. The major change was a shift from nuclear towards gas, with minor upward change toward renewables.

By 2007-08 most of these companies had built up their broad and integrated energy supply chains through ambitious mergers and acquisitions. They had also consolidated their business focus through sales of non-core business, thereby generating financial assets that allowed further expansion. The companies maintained a broad engagement along the whole energy value chain including competencies from generation, transmission, wholesale trading, distribution and retailing. Their product or value proposition was to develop integrated energy services, including electricity and gas, with a high security of supply at competitive prices.

2008 financial crisis and the following slowdown of the economy dealt a serious blow to the profitability of the incumbents in two geographies. The first step of recovery was to emphasize and enhance efficiency and consolidation as core foci. optimizing operating processes across the activities and reduce administrative costs, to build competitive advantage. A second step of administrative reform was to gradually introduce green energy as a more substantive area of focus, to build strength in the portfolio, thus aligning more with public energy policy with organizational focus for the future play. The distributed energy model locates electricity production with customers, typically based on installation of solar panels in flexible interplay with centralized energy supply.

The new emergent models are, in part, to expand toward new renewable upstream engagement, to concentrate on the customer interface, but not to go away from their heavily carbon based generation portfolios. From strategies of scale, scope and oligopolistic power based on conventional technologies, the energy industry is moving into new unchartered terrain characterized by greening, digitalization, decentralization and disruptive innovation.

For more reading: A Midttun et al Facing the climate and digital challenge: European energy industry from boom to crisis and transformation, Energy Policy, Volume 108, September 2017, Pages 330-343. 